\title{
Soft Tissue Expanders for Ridge Augmentation: A Review
}

\author{
Shalini Arumugam ${ }^{1}$,C. Burnice Nalina Kumari ${ }^{1}$, S. Ashok Kumar ${ }^{1}$, R. Vijayalakshmi ${ }^{1}$ \\ ${ }^{l}$ Department of Periodontology and Implantology, Faculty of Dentistry, \\ Meenakshi Academy of Higher Education and Research, Chennai. Tamilnadu, India
}

\begin{abstract}
Aesthetics in dentistry is one of the great concern for dental professionals as well as patients for maintenance of oral health. Missing tooth is the common esthetic problems in the patients which can be due to various periodontal or endodontic reasons. There are different treatment options available for replacing the missing tooth and the best alternative treatment is replacement using dental implants. Very often, placement of dental implants gets compromised when there is insufficient ridge or ridge defect. So when there is a ridge defect we need to definitely augment the ridge for the successful placement of dental implants. This article gives a short review about the tissue expanders used for ridge augmentation and their clinical efficiency of achieving a proper ridge morphology.
\end{abstract}

Keywords: Ridge Augmentation, Soft tissue Expanders, Implant.

\section{Introduction}

Missing tooth has become the common esthetic problem. Dental implant placement is one of the best treatment modalities. When there is ridge defect the placement of dental implant gets highly compromised. The correction of soft and hard tissue deficiency in such cases is a challenge for the clinician. Ongoing advances in periodontal surgeries permits the clinicians to reconstruct the insufficient soft tissue in alveolar edges with more unsurprising ways than already potential strategies. The deficiency of soft tissue in the alveolar ridge has been a challenge for the clinicians to achieve a proper augmentation outcome for patients with missing tooth. ${ }^{[1,2,3,4,5]}$ This article is an overview of tissue expanders in a predictable augmentation of defective alveolar ridges.

\section{Corresponding Author:}

\section{Dr. C. Burnice Nalina Kumari}

Department of Periodontology and Implantology, Faculty of Dentistry, Meenakshi Academy of Higher Education and Research, Chennai. Tamilnadu, India e-mail: drburnice.perio@madch.edu.in

\section{Ridge Defects:}

Alveolar ridge defects are classified into three types. They are:

1. Horizontal

2. Vertical

3. Combination

Different method to treat ridge defects have certain disadvantages such as flap transfer, color mismatch owing to different surgical site and loss of grafted bone. There is a new advanced alternative method namely soft tissue expander that holds an effective method to treat soft tissue deficiency. ${ }^{[6]}$ The tissue expanders reduce morbidity of the donor site.

\section{Horizontal ridge augmentation method:}

1. Autogenous bone grafting

2. Allogenous bone grafting

3. Ridge split technique

Vertical ridge augmentation method:

1. Guided bone regeneration (GBR)

2. Autologous local bone augmentation

3. Graft derived bone blocks 
Soft tissue expanders for alveolar augmentation:

History: The tissue expansion method was first introduced by NEUMANN and it was used on the skin for ear reconstruction. ${ }^{[7]}$ About 20 years later this tissue expansion method was developed by Austad and Rose in 1982; later Randovan et al developed self inflating tissue expanders. The self inflating tissue expanders require longer time to expand which is about to 8 to 14 weeks. ${ }^{[8]}$

Forms of soft tissue expanders: The tissue expanders exist in two forms; they are cylinder and cupola.

- In the straight edentulous region, the cylinder shaped tissue expander is normally used.

- And then in the curved frontal edentulous region, when one or more teeth is missing the cupola form of tissue expander is used. ${ }^{[10]}$

Classification of soft tissue expanders: Soft tissue expanders are of various types:

\section{Commercially available forms of tissue expanders: ${ }^{[14]}$}

1. Standard tissue expander

2. Custom-built expander

3. Differential expander

4. Anatomical expander

These tissue expanders are used in general medicine for various purposes like reconstruction of breast after mastectomy, ear and nose reconstruction surgeries, scar revision surgery, development of skin flap, skin pathology such as burns, vascular deformity, severe irregular scars and post-infection defects.

Tissue expanders in dentistry: In modern dentistry, various soft tissue expanders are being used in dentistry since 1990's. The various commercially available expanders are as follows:

\section{Osmed self-inflating tissue expander (Osmed GmbH, Germany):}

Mechanism: It is roofed by a perforated silicone shell to ensure the flow of body fluid. Continuous swelling of the expander occurs under a controlled condition.

Special feature: The gradual increase in size and volume of the expander stimulates the growth of additional soft tissues.
2. Mentor tissue expander (Mentor Worldwide LLC, Minneapolis):

\section{Mechanism:}

- Dacron-reinforced base allows directional expansion by providing a solid platform.

- Low risk of side-wall leakage due to its bottomloading design.

- Presence of remote injection dome.

Special Features: Used in reconstruction of facial features like lips, nose and eyelids. Various shapes are available: round, rectangular, elliptical and crescentshaped.

3. CUITM Brand Tissue Expander (Allergan,
California)

\section{Mechanism:}

- Consists of a silicone elastomer envelope, a remote injection dome and a patented fill valve, which allows high rate of inter-operative inflation.

- It is gradually inflated by injecting sterile saline solution at intervals until the required volume and size is obtained.

Special Features: Temporarily used for the development of skin flap and reconstruction of a defect to provide adequate coverage of prosthesis.

Osmed Self Inflating Tissue Expander: Osmed self inflating tissue expander was introduced by Osmed in the year 1999. This expander was used as a new option for tissue expansion in dentistry. This osmotic expander is of second generation and it was first investigated in-vitro to determine the mechanical and swelling properties. Osmotic self inflating tissue expander is expanded because of absorption of body fluids and it is made up of solid material such as methyl methacrylate or vinyl pyrrolidone, hydrogel; these materials absorb the surrounding tissue fluid and it will increase in size over a period of $6-8$ weeks. ${ }^{[15,16]}$

Method of Usage: The osmotic self inflating tissue expander should be coated with silicone shell which has multiple perforations which allows the influx in tissue fluids. The speed of rate of influx in volume increases over time and it gets controlled by the number of perforations. ${ }^{[17]}$ But the first generation of balloon expanders were not coated by silicone; these expanders get swollen slowly and continuously and the injection dependent peaks need to be avoided. 
These expanders are available in various sizes of $0.24,0.25,0.7,1.3$ or $2.1 \mathrm{ml}$. Surgical template should be used prior to the placement of the expander. ${ }^{[18]}$

Initial incision performed, submucosal pouch prepared using scalpel and scissors without elevating the periosteum. Using surgical template expander, the size of the pouch should be controlled. The expander has to be placed into the submucosal pouch using bone fixation screw. The surgical area will be sutured with two-layered sutures using a fine monofilament suture material. Antibiotics (amoxicillin 750mg) should be administered one hour before surgery and prescribed for 7 days. The analgesics (ibuprofen 400mg) should also be given for 7 days. Patient has to come for a weekly followup and advised to use $0.2 \%$ chlorhexidine mouthwash for 2 weeks. After 6-8 weeks of expansion, soft tissue expansion will be achieved for ridge augmentation ${ }^{[19]}$.

Mechanism: It is roofed by a perforated silicone shell to ensure the flow of body fluid. There is continuous swelling of the expander occur under a controlled condition.

\section{Advantages of soft tissue expanders:}

- Soft tissue expander is a simple surgical procedure; there is minimal infection and complication. ${ }^{[9]}$

- Delayed action is there whereby swelling commences after a predetermined period of time. ${ }^{[10]}$

- A precisely controlled expansion rate.

- Short surgical procedure, thus reducing postoperative pain. ${ }^{[11,12]}$

- Low cost of surgery.

\section{Disadvantages of soft tissue expanders:}

- It can over expand,

- Possibility of infection, serum formation and tissue necrosis.

- Silicone bag may get perforated.

- Hypoxia may occur due to quick expansion. ${ }^{[12]}$

- Vascularization of tissue is poor in the implantation site. $^{[13]}$

\section{Discussion}

"Creep" and mechanical and biological "stretch" are responsible for tissue expansion. This surgical tissue expander was historically invented by Neumann in 1957. It is scientifically proven from clinical studies that vertical ridge augmentation can be done using the principles of tissue expansion.

A second era osmotic expander was first examined in-vitro to decide mechanical and growing properties. The natural biologic properties of different soft tissue expansion, for example, skin or mucous layer, it responds to mechanical powers by tissue development bringing about cell proliferation. ${ }^{[20]}$ The hydrogel at expanders core is the result for mechanical properties of swelling and other parameters. Osmed self inflating tissue expanders, most normally utilized in dentistry was adequate to give a sufficient measure of soft tissue for ridge morphology. The requirement for external filling of body fluids is eliminated, which gives the low frequency of irresistible complexities by increasing the size by ingestion of body fluids.

In case reports, another expander used in specific is the intra-oral utilization of inflatable silicone balloon expander for bone graft surgeries. These expanders will be filled once in seven days by using injection and saline in subcutaneous infusion port until blanching appears in overlying tissues. Therefore this method is extremely technique sensitive and requires more surgical skills.

Also the supraperiosteal placement of hydrogel will prevent the significant resorption in the underlying bone which is seen with the subperiosteal expanders. And then the submucosal pouch is easily prepared. The swelling time is 60 days for hydrogels which is four times the silicone balloon and thus, this gives a prolonged discomfort to the patient. Also, slow and constant development will bring about protected and viable age of soft tissue with the osmotic expander.

The two significant histological changes happen during expansion are as follows: One is the fibrous capsule formation optional to an inordinate statement of collagen framework around implanted devices. A subsequent function happens at the bone surface, which fills in as a counter-bearing territory for the expansile pressure applied by expanders. Fibrous capsule formation is a complicated multifactorial process. Fibrous capsule formation is a muddled multifactorial cycle where the capsule severity has a positive direct relationship with the level of nearby inflammatory responses ${ }^{[21]}$.

The vertical ridge augmentation in return will effectively prove the success rate for prosthetic rehabilitation of missing teeth and gives a high patient satisfaction. 


\section{Conclusion}

Soft tissue expander is a simple surgical procedure which gives minimal complications and the incidence rate is low in graft exposition after augmentation surgery. Soft tissue expander using the osmotic tissue expander has more advantages over inflatable silicone balloons for vertical ridge augmentation The tissue expander seems to be a more effective method in developing minimal amount of tissue after a surgical procedure. The soft tissue expander provides better and adequate tissue coverage and aesthetics. The use of soft tissue expander has started gaining more attention towards the surgical procedures, hence it has more advantages which can overcome the problem such as loss of bone graft and disclosure of bone graft. Based on the numerous responses from patients for esthetics, form and function, the tissue expander is expected to play an important part in intra-oral reconstruction in the future.

\section{Ethical Clearance: Nil}

Source of Funding: Meenakshi Academy of Higher Education and Research, Chennai, India.

\section{Conflict of Interest: Nil}

\section{References}

1. Bahat O, Koplin LM. Pantographic lip expansion and bone grafting for ridge augmentation. The International journal of periodontics \& restorative dentistry. 1989;9(5):344.

2. Pikos MA. Mandibular block autografts for alveolar ridge augmentation. Atlas of the oral and maxillofacial surgery clinics of North America. 2005 Sep 1;13(2):91-107.

3. Peleg M, Sawatari Y, Marx RN, Santoro J, Cohen J, Bejarano P, Malinin T. Use of corticocancellous allogeneic bone blocks for augmentation of alveolar bone defects. International Journal of Oral \& Maxillofacial Implants. 2010 Jan 1;25(1).

4. Bahat O, Deeb C, Golden T, Komarnyckij O. Preservation of ridges utilizing hydroxyapatite. The International journal of periodontics \& restorative dentistry. 1987;7(6):34.

5. Nyman S, Lang NP, Buser D, Brägger U. Bone regeneration adjacent to titanium dental implants using guided tissue regeneration: a report of two cases. International Journal of Oral \& Maxillofacial Implants. 1990 Mar 1;5(1).
6. Cunha MS, Nakamoto HA, Herson MR, Faes JC, Gemperli R, Ferreira MC. Tissue expander complications in plastic surgery: a 10-year experience. Revista do Hospital das Clínicas. 2002 Jun;57(3):93-7.

7. Austad ED, Rose GL, Radovan C. A self-inflating tissue expander. Plastic and reconstructive surgery. 1982 Nov 1;70(5):594.

8. Wiese KG. Osmotically induced tissue expansion with hydrogels: a new dimension in tissue expansion? A preliminary report. Journal of CranioMaxillofacial Surgery. 1993 Oct 1;21(7):309-13.

9. Austad ED, Rose GL, Radovan C. A self-inflating tissue expander. Plastic and reconstructive surgery. 1982 Nov 1;70(5):594.

10. Hallock GG. Tissue expansion techniques to minimize morbidity of the anterolateral thigh perforator flap donor site. Journal of reconstructive microsurgery. 2013 Nov;29(09):565-70.

11. Pasyk KA, Austad ED, McClatchey KD, Cherry GW. Electron microscopic evaluation of guinea pig skin and soft tissues" expanded" with a selfinflating silicone implant. Plastic and reconstructive surgery. 1982 Jul 1;70(1):37-45.

12. Sharobaro VI, Moroz VY, Starkov YG, Strekalovsky VP. First experience of endoscopic implantation of tissue expanders in plastic and reconstructive surgery. Surgical Endoscopy And Other Interventional Techniques. 2004 Mar 1;18(3):513-7.

13. Dhadse PV, Yeltiwar RK, Bhongade ML, Pendor SD. Soft tissue expansion before vertical ridge augmentation: Inflatable silicone balloons or selffilling osmotic tissue expanders? Journal of Indian Society of Periodontology. 2014 Jul;18(4):433.

14. Wagh MS, Dixit V. Tissue expansion: Concepts, techniques and unfavourable results. Indian journal of plastic surgery: official publication of the Association of Plastic Surgeons of India. 2013 May;46(2):333.

15. Ronert MA, Hofheinz H, Manassa E, Asgarouladi $\mathrm{H}$, Olbrisch RR. The beginning of a new era in tissue expansion: self-filling osmotic tissue expanderfour-year clinical experience. Plastic and Reconstructive Surgery. 2004 Oct 1;114(5):102531.

16. Jensen SS, Terheyden H. Bone augmentation procedures in localized defects in the alveolar 
ridge: clinical results with different bone grafts and bone-substitute materials. InDatabase of Abstracts of Reviews of Effects (DARE): Quality-Assessed Reviews [Internet] 2009. Centre for Reviews and Dissemination (UK).

17. Anwander T, Schneider M, Gloger W, Reich RH, Appel T, Martini M, Wenghoefer M, Merkx M, Bergé $\mathrm{S}$. Investigation of the expansion properties of osmotic expanders with and without silicone shell in animals. Plastic and reconstructive surgery. 2007 Sep 1;120(3):590-5.

18. Tominaga K, Matsuo T, Kuga Y, Mizuno A. An animal model for subperiosteal tissue expansion. Journal of oral and maxillofacial surgery. $1993 \mathrm{Nov}$ 1;51(11):1244-9.
19. Stuehmer C, Rücker M, Schumann P, Bormann KH, Harder Y, Sinikovic B, Gellrich NC. Osseous alterations at the interface of hydrogel expanders and underlying bone. Journal of Cranio-Maxillofacial Surgery. 2009 Jul 1;37(5):258-62.

20. Neumann CG. The expansion of an area of skin by progressive distention of a subcutaneous balloon: use of the method for securing skin for subtotal reconstruction of the ear. Plastic and reconstructive surgery. 1957 Feb 1;19(2):124-30.

21. Poeppl N, Schreml S, Lichtenegger F, Lenich A, Eisenmann-Klein M, Prantl L. Does the surface structure of implants have an impact on the formation of a capsular contracture?. Aesthetic plastic surgery. 2007 Apr 1;31(2):133-9. 